\title{
La consideración moral de los animales: Jesús Mosterín y la tauromaquia*
}

\author{
The moral consideration of animals: \\ Jesús Mosterín and bullfighting
}

DANIEL DORADO ALFARO**

\begin{abstract}
Resumen: Nota crítica sobre el libro de Jesús Mosterín A favor de los toros, Pamplona, Laetoli, 2010.
\end{abstract}

Palabras clave: ética, ética aplicada, ética animal.

\begin{abstract}
Critical Note on the book of Jesús Mosterín A favor de los toros, Pamplona, Laetoli, 2010.

Keywords: ethics, applied ethics, animal ethics.
\end{abstract}

En los últimos años se ha producido un considerable aumento del número de publicaciones dedicadas al estudio de la consideración moral de los animales, tendencia que viene acompañada de una mayor especialización en dichas obras. ${ }^{1}$ A favor de los toros es una nueva muestra del trabajo que se ha venido realizando en este campo de estudio. Su autor, Jesús Mosterín, se ha caracterizado por tocar disciplinas filosóficas de lo más variadas. En este libro realiza una crítica, en concreto, de la tauromaquia, presentando toda una serie de razones que, a su juicio, le llevan a concluir que esta actividad resulta moralmente indefendible.

El libro de Mosterín no contiene únicamente argumentos de carácter moral, pues una parte importante de la introducción y de los dieciséis capítulos que conforman esta obra tiene como objeto describir el contexto en el que se desarrolla la discusión. Para ello destina abundantes páginas a hablar de cuestiones como los antecedentes históricos de la tauromaquia, sus distintas manifestaciones actuales o la fisiología de los bovinos. Estas cuestiones resultan de gran interés, y hacen que la lectura del libro sea ciertamente amena, si bien en muchos casos resultan tangenciales a la cuestión central que se está tratando en el mismo.

Mosterín abre su ensayo dejando claro en la introducción que no considera que la tauromaquia sea «el problema moral más grave que plantea nuestra relación con los animales

Fecha de recepción: 06/ 04/ 2012. Segunda versión: 27/ 01/ 2013. Fecha de aceptación: 11/ 02/ 2013.

* Deseo dar las gracias a Emilio José Armaza, Gianella de la Asunción, David Díaz y Oscar Horta por los comentarios a los borradores previos de este texto.

** Universidad Carlos III de Madrid. Contacto: danieldorado@outlook.com

1 Cfr. D. Dorado: «La consideración moral de los animales no humanos en los últimos cuarenta años: una bibliografía anotada», Télos. Revista iberoamericana de estudios utilitaristas, vol. 17, 2010, pp. 47-64, disponible en http://www.usc.es/revistas/index.php/telos/article/view/282 [ref. de 26 de enero de 2013]. 
no humanos $»^{2}$. Prosigue señalando que «la ganadería intensiva es, desde una perspectiva global, más importante y difícil que el de la tauromaquia». ¿Cuál es el motivo, entonces, de que tanto este libro como una buena parte de las publicaciones del autor estén centrados en el citado espectáculo? Podemos entender que responde a la anterior pregunta al afirmar lo siguiente: «Hay maltratos de animales cuya solución es compleja, dada su insistencia en la alimentación o la investigación, por ejemplo. No así las corridas de toros ni las salvajadas pueblerinas, que no sirven para nada y representan una masa de sufrimiento inútil, perfectamente prescindible y fácilmente evitable». ${ }^{4}$

Tras la introducción, los capítulos que van del 1 al 6 constituyen una especie de prólogo al trato de la cuestión en términos propiamente morales, a través del cual Mosterín va presentando y discutiendo una serie de datos para que conozcamos el contexto de la discusión acerca de la tauromaquia. No obstante, en estos ya presenta algunas consideraciones de carácter moral. Así, dedica el capítulo 1 («Biología de los toros») a exponer las principales características biológicas y taxonómicas de los toros. Esta cuestión, en principio, no tendría por qué implicar ninguna disputa en términos morales: uno de los objetivos de Mosterín al realizar esta exposición es preparar una respuesta al argumento según el cual los toros de lidia desaparecerían si no existiera la tauromaquia, empleado profusamente por los aficionados a la tauromaquia. Mosterín señala al respecto lo siguiente: «El llamado toro bravo no constituye una especie, ni siquiera una subespecie: pertenece a la misma especie y subespecie que el resto de los toros, bueyes y vacas, aunque conserva un aspecto relativamente próximo al toro original, pues no ha sido sometido a los extremos de selección artificial que han sufrido algunas variedades de vacas». ${ }^{5}$ Pero el hecho es que, al entrar a debatir esta cuestión, asume de manera implícita que es moralmente relevante el hecho de que los toros empleados en la tauromaquia formen o no una especie. Sin embargo, esto es algo que rechazaremos si defendemos que lo relevante a la hora de considerar moralmente a un individuo no es su pertenencia a una determinada especie ni el número de individuos de esta, sino el hecho de que posea un sistema nervioso central y, por tanto, capacidad de sufrir y disfrutar. De esta manera, vemos que Mosterín adopta aquí posiciones en común con sus oponentes teóricos, y pasa a convertir una cuestión que podríamos considerar totalmente tangencial al debate sobre la tauromaquia en un asunto moral.

El capítulo 2 («Maltrato humano a los bovinos») muestra ejemplos de matanzas y explotación provocadas históricamente a los animales de esta subfamilia de mamíferos; concretamente menciona de manera crítica la caza de bisontes realizada en Norteamérica y Europa, y de los bóvidos en África. En este capítulo señala que hay 1.400 millones de toros y vacas en la ganadería, pero dicha afirmación la realiza en apoyo de la idea de que la especie de los toros no se encuentra en una situación de posible extinción. ${ }^{6}$ Si bien Mosterín podría aprovechar este momento para cuestionar moralmente la cría de animales para fines alimenticios, que lleva a que cada año sean criados y matados un número notable de bóvidos, entre otros animales, deja pasar esta ocasión por razones que discutiremos más abajo y que tienen que ver con inconsistencias de su propia posición.

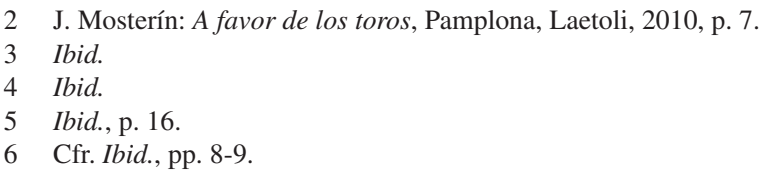


En el capítulo 3 («La cultura de la crueldad»), Mosterín explica por qué la tauromaquia constituye una tradición cultural, afirmación que ha constituido un argumento común a favor de esta práctica por parte de sus defensores. Ante este argumento, Mosterín no procede negando la corrección de la premisa en la que descansa, sino rechazando que de ella se siga ninguna clase de justificación. Según Mosterín, «[c]ultura es toda la información transmitida por aprendizaje social, y esto incluye ideas y costumbres de todo tipo». ${ }^{7}$ Pero que algo forme parte de nuestro acervo cultural, como ocurre con la tauromaquia, no significa que sea moralmente aceptable, como bien señala Mosterín. ${ }^{8}$

Los siguientes tres capítulos tienen como objeto presentar las distintas manifestaciones que ha tenido y tiene a día de hoy la tauromaquia, así como otros espectáculos consistentes en agresiones a los animales. El capítulo 4 («Espectáculos de la crueldad»), hace un recorrido histórico por estos, desde el Imperio Romano hasta la actualidad. En el capítulo 5 («Fiestas de toros») describe cómo se han celebrado tradicionalmente los espectáculos donde eran usados toros, y en el capítulo 6 («La actual corrida de toros») señala la estructura de este espectáculo en la actualidad.

En el capítulo 7 ( «A favor y en contra de la tauromaquia»), Mosterín expone brevemente la promoción de la tauromaquia realizada desde las instituciones políticas en España a partir de Fernando VII. Indica también una serie de personajes de relevancia histórica e intelectuales que fueron favorables a la tauromaquia (José Ortega y Gasset, Fernando Savater, Mario Vargas Llosa...) y detractores de la misma (Mariano José de Larra, Bernardo O’Higgins, Santiago Ramón y Cajal, Rosa Montero...).

Los capítulos 8 a 14 recogen varios artículos publicados por Mosterín durante la campaña por la abolición de la tauromaquia en Cataluña, y revisados por el autor. En estos capítulos presenta distintos argumentos ya empleados en el resto del libro, pero con un tono más divulgativo. El capítulo 13 («El triunfo de la compasión») es una edición revisada del artículo del mismo nombre, respondido en su momento por Fernando Savater, ${ }^{9}{ }^{10}$ y que incluye una apostilla en la que Mosterín realiza una réplica a Savater. Mosterín argumenta en este capítulo que del hecho de que otros animales sufran no se deriva que no deba existir una oposición a la tauromaquia, y que del hecho de que la tauromaquia sea una tradición española no se deriva que su celebración sea moralmente correcta.

El libro termina con el capítulo 15 («Argumentos fallidos en defensa de la tauromaquia»), en el cual expone siete de los argumentos más conocidos de entre los que han sido tradicionalmente alegados por quienes defienden la conservación del espectáculo analizado, a los cuales responde. Es este capítulo el de mayor interés filosófico, habida cuenta de que es en el mismo donde Mosterín condensa su refutación de los argumentos manejados por los defensores de la tauromaquia. Se exponen a continuación los argumentos de estos en cursiva, y seguidamente la posición mantenida por Mosterín:

$7 \quad$ Ibid., p. 23.

8 Cfr. Ibid., pp. 23-25.

9 F. Savater: «Lección de lógica», El País, 11 de mayo de 2010, disponible en: http://elpais.com/diario/2010/05/11/ opinion/1273528809_850215.html [ref. de 11 de febrero de 2013].

10 Puede encontrarse una exposición de las ideas de Savater sobre la tauromaquia en F. Savater: Tauroética, Madrid, Turpial, 2010. 
1. Las corridas son crueles, pero también hay muchas otras salvajadas en el mundo. Mosterín responde que la existencia de otras prácticas moralmente injustificables en el mundo no justifica la existencia de la tauromaquia, y que son varias las «formas de crueldad» con las que acabar.

2. La corrida de toros es tradicional y eso la justifica. La respuesta dada por Mosterín es que «[a]ceptar ciegamente todos los componentes de la tradición es negar la posibilidad misma del progreso de la cultura». ${ }^{11}$ Este razonamiento es complementado con la enumeración de diversas prácticas tradicionales cuyas víctimas son humanas, y que son ampliamente rechazadas en nuestra sociedad. El autor busca de esta manera mostrar que el carácter tradicional de una práctica no implica que esta sea moralmente aceptable.

3. Los toros no sufren. La respuesta, en este caso, es que tal afirmación carece de toda base. Mosterín apunta: «[1] os neurólogos no sólo saben perfectamente que el toro es capaz de sufrir, puesto que las estructuras neurales de su diencéfalo y de su sistema límbico son semejantes a las nuestras, sino que a veces lo usan como modelo en estudios sobre el dolor». ${ }^{12}$

4. Los toros sí sufren, pero antes lo pasan bien. Este es un argumento comparativo, apoyado en la asunción de que consideramos justificado explotar a otros bovinos en condiciones peores que aquellas en las que se encuentran los toros usados en la tauromaquia. Mosterín reconoce esto, indicando que muchos de los toros empleados en la tauromaquia viven «mucho mejor que la mayoría de las vacas, y sobre todo que las pobres víctimas de los establos intensivos de concentración». ${ }^{13} \mathrm{Y}$ está de acuerdo con que esto último supone un problema. Ahora bien, la solución que ofrece al respecto no es de carácter abolicionista, como sí defiende en el caso de la tauromaquia. Mosterín no cuestiona la práctica de la ganadería, pues sostiene únicamente que «hay que mejorar las condiciones de vida de las vacas lecheras». ${ }^{14}$

5. Sin corridas, los toros de lidia y las dehesas en que se crían desaparecerían. Mosterín responde al respecto que «la especie y subespecie de los toros (Bos primigenius taurus), con unos 1.400 millones de ejemplares vivos, no está precisamente en peligro de extinción», ${ }^{15}$ y prosigue defendiendo que, para conservar las características originales de los toros «de lidia», sería preferible que estos «dejaran de ser animales de ganadería para convertirse en animales salvajes, sometidos a la selección natural de los predadores y el entorno más bien que a la selección artificial encaminada a suministrar animales debilitados a los toreros». ${ }^{16}$ Tras señalar que los animales bovinos pueden vivir en la naturaleza, para lo cual pone como ejemplos a bisontes y búfalos acuáticos, señala que sería «muy conveniente» que, una vez abolidas las corridas de toros, los toros y vacas pudieran vivir en las dehesas, reconvertidas en reservas naturales protegidas, «compartiendo el territorio con otras especies, incluso con lobos reintroducidos, que servirían para mantener la salud de la población de bovinos (como ha pasado recientemente en Yellowstone)». ${ }^{17}$

6. Las corridas dan de comer a cierta gente que sin ellas se quedaría sin trabajo. Mosterín responde a esto indicando que hay maneras de ganarse la vida sin ocasionar daños a otros, y apuesta por escuelas de reconversión profesional para picadores y toreros.

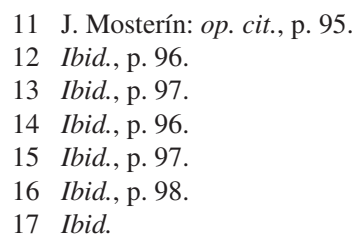


7. No hay que prohibir las corridas de toros porque no hay que prohibir nada: prohibido prohibir. Mosterín, tras criticar que quienes defienden el citado argumento sí que son partidarios de prohibir determinadas prácticas, señala que la libertad no es «una patente de corso para cometer crueldades y salvajadas contra víctimas inocentes», ${ }^{18}$ sino «la capacidad de dos seres humanos adultos y cuerdos de interactuar entre ellos como quieran, siempre que sea de un modo voluntario para ambas partes (consenting adults) y su derecho a hacerlo sin interferencia de terceros». ${ }^{19}$ Afirma también al respecto que la libertad «exige y va siempre acompañada de la prohibición de violencias y crueldades de todo tipo». ${ }^{20}$

Nada puede objetarse a las respuestas dadas por Mosterín a los argumentos 1, 2, 3, 6 y 7. Sin embargo, resultan problemáticas las que realiza a los argumentos 4 y 5 , por lo que se indicará a continuación. Sostendré que estas últimas respuestas manejadas por Mosterín no van en línea con un planteamiento netamente comprometido con la consideración moral de los animales animales, pues en las publicaciones que abordan esta cuestión juega un papel central el concepto especismo, es decir, la consideración o trato desventajoso injustificado de aquellos que son clasificados como pertenecientes a ciertas especies. ${ }^{21}$ Las respuestas dadas por Mosterín a los argumentos 4 y 5 pueden ser consideradas especistas.

Mosterín señala en la respuesta al argumento 4 («los toros sí sufren, pero antes lo pasan bien») que deben mejorarse las condiciones de vida de las vacas criadas para la obtención de leche destinada al consumo humano. Argumenta esto desde una postura que defiende como posicionada del lado de la consideración moral de los animales. Sin embargo, desde tal posicionamiento puede apuntarse que el hecho de que las vacas sean criadas y destinadas a la producción de carne y leche es moralmente objetable con independencia de las condiciones en que dicha actividad se realice. Las vacas, aunque se produzcan cambios en cuanto a la regulación legal de su trato, seguirán sufriendo, separadas de sus crías, y siendo matadas junto con estas cuando ello resulte rentable en términos económicos. Si rechazamos aplicar este trato en el caso de humanos, también deberíamos rechazar aplicarlo en el caso de los animales de otras especies. Por ese motivo, la única solución aceptable desde un punto de vista crítico con el especismo es dejar de criar y usar a los animales, algo que solo ocurrirá en la medida en que los ciudadanos dejen de consumir productos de origen animal.

En cuanto a la respuesta dada al argumento 5 («sin corridas, los toros de lidia y las dehesas en que se crían desaparecerían»), se puede decir que resulta problemática por múltiples motivos, como los siguientes: no está teniendo en cuenta el posible desvalor existente en dichos ecosistemas;22 asume que la conservación de los toros como especie tiene un valor intrínseco, la cual es una posición rechazable porque asigna valor a una categoría taxonómica como la especie, y no a los individuos con la capacidad de sufrir

18 Ibid., p. 100.

19 Ibid.

20 Ibid.

21 O. Horta: «What Is Speciesism?», Journal of Agricultural and Environmental Ethics, vol. 23, 2010, p. 247.

22 Cfr. Y.-K. Ng: «Towards Welfare Biology: Evolutionary Economics of Animal Consciousness and Suffering», Biology and Philosophy, ${ }^{\circ}$ 10, 1995, pp. 255-285; M. Clark y Y.-K. Ng: «Population Dynamics and Animal Welfare: Issues Raised by the Culling of Kangaroos in Puckapunyal», Social Choice and Welfare, vol. 27, $\mathrm{n}^{\circ}$ 2, 2006, pp. 407-422; O. Horta: «La cuestión del mal natural: bases evolutivas de la prevalencia del desvalor», Ágora: Papeles de Filosofía, vol. 30, nº 2, 2011, pp. 57-75, disponible en http://dspace.usc.es/ handle/10347/7395 [ref. de 26 de enero de 2013]. 
y disfrutar; y la defensa que Mosterín realiza de una situación donde existe depredación supone no tener en consideración los intereses de los individuos depredados. ${ }^{23}$ Además, Mosterín pone como ejemplo de una adecuada política de conservación la llevada a cabo en el Parque de Yellowstone, donde se introdujeron lobos a mediados de la década de los 90 con la intención, entre otras, de controlar la población de cérvidos (en concreto, de uapitíes, también llamados ciervos canadienses). Esta medida ha supuesto que miles de cérvidos hayan sido devorados, y que otros tantos hayan sufrido problemas nutricionales al no acercarse a las praderas por temor a los lobos, lo cual provoca que se alimenten exclusivamente de arbustos y ramas de árboles. ${ }^{24} \mathrm{Si}$ rechazamos el especismo y nos oponemos a que se introduzcan en las ciudades depredadores que maten a humanos con el objetivo de regular la población de estos, también debemos oponernos a esta práctica cuando las víctimas son animales de otras especies. En definitiva, la respuesta de Mosterín a este argumento muestra claramente que no tiene en consideración igualitaria los intereses de los animales, sino que, por el contrario, se está adhiriendo a los postulados de la ética ambiental, los cuales no reivindican que los animales no humanos sean tenidos en consideración moral por el hecho de ser individuos sintientes. ${ }^{25}$

Como vemos, la posición moral de Mosterín al respecto de los animales cae en una discriminación especista. Otro ejemplo de ello es que no rechaza el consumo de productos de origen animal, y que tampoco rechaza el uso de animales no humanos para la investigación biomédica (posición que no va acompañada de una defensa del uso de humanos para la investigación biomédica sin el consentimiento de estos). Sencillamente defiende que dichas prácticas han de ser reguladas para reducir el sufrimiento infligido a los animales, postura diferente de la mantenida en lo relativo a la tauromaquia, práctica cuya abolición sostiene.

Este planteamiento de Mosterín se relaciona con su razonamiento, apuntado más arriba, según el cual la diferencia que se puede encontrar entre la alimentación y la investigación biomédica, de una parte, y la tauromaquia, de otra, es que aquellas sirven

23 Cfr. S. F. Sapontzis: «La depredación», Télos: Revista iberoamericana de estudios utilitaristas, vol. 17, 2010, pp. 91-105, disponible en http://www.usc.es/revistas/index.php/telos/article/view/285/251 [ref.: de 23 de enero de 2013]; L. C. Cunha: «O princípio da beneficência e os animais não-humanos: uma discussão sobre o problema da predação e outros danos naturais», Ágora: Papeles de Filosofía, vol. 30, no 2, 2011, pp. 99-131, disponible en http://hdl.handle.net/10347/7399 [ref. de 22 de enero de 2013]; C. K. Fink: «El argumento de la depredación», Ágora: Papeles de Filosofía, vol. 30, n 2, 2011, pp. 135-146, disponible en http://dspace.usc.es/ handle/10347/7400 [ref. de 23 de enero de 2013.

24 Cfr. O. Horta: «The Ethics of the Ecology of Fear against the Nonspeciesist Paradigm: A Shift in the Aims of Intervention in Nature», Between the Species, vol. 13, n 10, 2010, pp. 163-187, http://digitalcommons.calpoly. edu/cgi/viewcontent.cgi?article=1114\&context=bts [ref. de 11 de febrero de 2013].

25 Para un análisis de las diferencias entre la ética animal y la ética ambiental, realizado por autores adheridos a la primera, Cfr. Y. Bonnardel: «Contre l'apartheid des espèces: à propos de la prédation et de l'opposition entre écologie et libération animale», Cahiers Antispécistes, n 14, 1996, disponible en http://www.cahiersantispecistes.org/spip.php?article103 [ref. de 11 de febrero de 2013]; C. Faria: «Sobre o bem de tudo e de todos: a conjunção impossível entre ambientalismo e libertação animal», Ágora: Papeles de Filosofía, vol. 30, n 2, 2011, pp. 27-41, disponible en http://dspace.usc.es/handle/10347/7392 [ref. de 21 de enero de 2013]. Para un análisis de las diferencias realizado por partidarios de la ética ambiental, Cfr. E. C. Hargrove (ed.): The Animal Rights/Environmental Ethics Debate. The Environmental Perspective, Albany, State University of New York Press, 1992; M. Sagoff: «Animal Liberation and Environmental Ethics: Bad Marriage, Quick Divorce», en: M. E. Zimmerman, J. B. Callicott, G. Sessions, K. J. Warren y J. Clark (eds.): Environmental Philosophy: From Animal Rights to Radical Ecology, Englewood Cliffs, Prentice Hall, 1993, pp. 84-94. 
para algo y representan un sufrimiento que es útil, imprescindible o difícilmente evitable. Sin embargo, es difícil que algo no sirva realmente para nada, pues todo aquello que propicia conseguir un objetivo sirve para algo, con independencia de si el objetivo es moralmente aceptable o inaceptable. No es cierto que las corridas de toros y el resto de espectáculos con animales no sirvan para nada, puesto que sirven para divertir o entretener a quienes son aficionados a ellos, para que los criadores de animales obtengan un beneficio económico, para que haya individuos que mantengan relaciones sociales con otros, etc., si bien todo esto no justifica la celebración de dichos eventos. Cabe señalar también que el consumo de alimentos de origen animal también sirve para algo: para que haya individuos que obtengan placer degustando sabores, para que los criadores de animales obtengan un beneficio económico, para que haya individuos que mantengan relaciones sociales con otros, etc., si bien podemos prescindir del consumo de esos productos y tener una buena salud. ${ }^{26}$

Es cierto que, en lo que respecta a la investigación biomédica, existe la posibilidad de que algunos experimentos realizados en animales no humanos sean de utilidad para el avance científico. Sin embargo, en el caso de ser así, esto no implicaría necesariamente que realizar dichos experimentos fuera moralmente correcto. De hecho, realizar experimentos en humanos secuestrados sería más útil para el avance científico, pero la inmensa mayoría de la sociedad considera esto moralmente inaceptable.

Podemos concluir que la diferenciación radical realizada por Mosterín entre los espectáculos con animales y otras formas de explotación animal no es anecdótica, sino muy representativa de su posición sobre la consideración moral de los animales. Si partimos de una posición que considera moralmente a los individuos sintientes, llegaremos a la conclusión de que Mosterín no está realmente a favor de los toros, pese al título de este libro. Cuando alguien está a favor de otros, busca que estos no sufran y no mueran. Pues bien, millones de animales sufren en las granjas y mueren en los mataderos cada día, y muchos más peces y otros animales marinos sufren y mueren al ser sacados del agua mediante redes de pesca. El interés de estos animales en no sufrir es tan importante para ellos como el de los toros que son matados en la tauromaquia, y como el de cualesquiera otros individuos sintientes, incluyendo los humanos.

Mosterín finaliza su libro criticando lo que considera una «flagrante contradicción»:27 abolir las corridas de toros en Cataluña y, a la vez, mantener los correbous. ${ }^{28}$ Tiene razón en esto, pues tanto las corridas de toros como los correbous son eventos donde se perjudica igualmente a animales. Pero, extendiendo este razonamiento, deberíamos llegar a la conclusión de que supone asimismo una contradicción oponerse a las corridas de toros y defender el consumo de productos de origen animal, pues ambos casos «representan una

26 Cfr. W. J. Craig; y A. R. Mangels: «Position of the American Dietetic Association: Vegetarian Diets», Journal of the American Dietetic Association, vol. 109, 2009, pp. 1266-1282. Disponible en: http://www.vrg.org/nutrition/2009_ADA_position_paper.pdf [ref. de 11 de febrero de 2013]. Traducción disponible en: http://www. grep-aedn.es/documentos/vegetariandiets.pdf [ref. de 11 de febrero de 2013].

27 J. Mosterín: op. cit., p. 105.

28 Se denomina correbous a una serie de espectáculos tradicionales realizados en Cataluña, especialmente en la provincia de Tarragona, consistente en diferentes tipos de encierros de toros o vacas. 
masa de sufrimiento inútil, perfectamente prescindible y fácilmente evitable». ${ }^{29}$ En definitiva, el problema de fondo en los argumentos que presenta Jesús Mosterín tanto en este libro como en otros (Los derechos de los animales ${ }^{30}$, ;Vivan los animales! ${ }^{31}$, etc.) es que de sus planteamientos no se deriva realmente una apuesta coherente por la consideración moral de los animales no humanos.

29 J. Mosterín: op. cit., p. 7.

30 J. Mosterín: Los derechos de los animales, Barcelona, Círculo de Lectores, 1995.

31 J. Mosterín: ;Vivan los animales!, Barcelona, Debate, 1998.

Daímon. Revista Internacional de Filosofía, nº 61, 2014 